\title{
Chemical Characterization and Antidiabetic Activity of Essential Oils from Pelargonium graveolens Leaves
}

\author{
Javed Ahamad $^{1}$ and Subasini Uthirapathy ${ }^{2}$ \\ ${ }^{1}$ Department of Pharmacognosy, Faculty of Pharmacy, Tishk International University, \\ Kurdistan Region, Erbil, Iraq \\ ${ }^{2}$ Department of Pharmacology, Faculty of Pharmacy, Tishk International University, \\ Kurdistan Region, Erbil, Iraq
}

\begin{abstract}
Pelargonium graveolens (Geranium) is a source of finest quality of fragrance and its essential oils (EOs) are used as antibacterial and antifungal agent. The aim of the current research is to determine chemical constituents in EO of $P$. graveolens by gas chromatography-mass spectrometry (GC-MS) and evaluate its antidiabetic activity through $\alpha$-glucosidase inhibition assay. The chemical composition of $\boldsymbol{P}$. graveolens $\mathrm{EO}$ was determined by GC/MS and its antidiabetic activity was assessed through inhibition of $\alpha$-glucosidase enzyme in in vitro models. GC-MS analysis determines 36 chemical components in the EO of P. graveolens leaves, and citronellyl isovalerate (10.41\%), menthol $(9.61 \%)$, linalool $(8.63 \%)$, p-menthone $(6.31 \%)$, and geranyl tiglate $(4.99 \%)$ were recorded as major constituents. The EO of $P$. graveolens leaves showed concentration-dependent inhibition of $\alpha$-glucosidase enzyme ranging from $28.13 \pm 1.41$ to $74.24 \pm 2.53 \%$ for concentration ranging from 31.25 to $1000 \mu \mathrm{g} / \mathrm{mL}$, respectively. The $\mathrm{IC}_{50}$ values for of $\boldsymbol{P}$. graveolens and acarbose were found as $93.72 \pm$ 4.76 and $80.4 \pm 2.17 \mu \mathrm{g} / \mathrm{mL}$, respectively, against the $\alpha$-glucosidase enzyme. The study finding explores the chemical components of $P$. graveolens growing in Iraqi Kurdistan region and scientifically supported its possible use in diabetic patients for controlling postprandial hyperglycemia.
\end{abstract}

Index Terms - Pelargonium graveolens, Geranium, Geraniaceae, Diabetes, Gas chromatography-mass spectrometry, $\alpha$-Glucosidase enzyme.

\section{INTRODUCTION}

Medicinal plants have emerged as major source drugs for the treatment of chronic diseases such as cancer, diabetes, and cardiovascular complications. Natural products derived from medicinal plants are considered safe and effective compared

\section{ARO-The Scientific Journal of Koya University}

Volume. IX, No.1 (2021), Article ID: ARO.10791, 5 pages

DOI:10.14500/aro.10791

Received: 24 February 2021; Accepted: 22 June 2021

Regular research paper: Published: 30 June 2021

Corresponding author's e-mail: javed.ahamad@tiu.edu.iq

Copyright (C) 2021 Javed Ahamad, Subasini Uthirapathy. This is an open-access article distributed under the Creative Commons Attribution License. to synthetic modern drugs based on the long history of use by humans as food and medicine (Ahamad, et al., 2019). Diabetes is a chronic disorder of metabolism caused by an absolute or relative lack of insulin and characterized by hyperglycemia, glycosuria, and hyperlipidemia (Gin and Rigalleau, 2000). The number of people in the world with diabetes has increased dramatically over recent years. Postprandial hyperglycemia (PPHG) is one of the key risk factors associated with diabetes. PPHG results due to the fast uptake of glucose in the intestine under the influence of hydrolyzing enzymes $\alpha$-amylase and $\alpha$-glucosidase that change polysaccharides through oligosaccharides to monosaccharides (Subramanian, Asmawi and Sadikun, 2008). Inhibition of $\alpha$-amylase and $\alpha$-glucosidase enzymes leads to a reduction in their hydrolysis and thereby controlled blood glucose levels (Dong, Li, Zhu, Liu and Huang, 2012). Therefore, an important strategy for managing PPHG is to inhibit $\alpha$-amylase and $\alpha$-glucosidase enzymes (Scheen, 2003). The $\alpha$-amylase and $\alpha$-glucosidase enzyme inhibitors as therapeutic agents are being increasingly pursued. These enzymes are preferred targets for the management of PPHG particularly in prediabetics or those with impaired glucose tolerance (Ahamad, Naquvi, Mir and Ali, 2011). Natural products as $\alpha$-amylase and $\alpha$-glucosidase inhibitors have attracted considerable interest in the drug discovery endeavors (Ahamad, Hasan, Amin and Mir, et al., 2016; Ahamad, Alkefai, Amin and Mir, 2020; Alkefai, Ahamad, Amin and Mir, et al., 2018; Alkefai, Ahamad, Amin and Mir, 2018). The clinically used inhibitors of carbohydrate metabolizing enzymes such as acarbose, voglibose, and miglitol are non-specific in their action. This results in side effects such as flatulence and distension caused due to bacterial fermentation of undigested carbohydrates. Thus, the search for selective inhibitors of these enzymes is still on and more and more medicinal plants are being screened continuously. Screening of traditionally used plants for the drug discovery process is often advocated as the chances of success using this approach are more (Fabricant and Farnsworth, 2001).

Pelargonium genus belonging to the family Geraniaceae and contains about 250 species (such as Pelargonium 
graveolens, Pelargonium capitatum, Pelargonium zonale, Pelargonium roseum, and Pelargonium odoratissimum). Pelargonium is distributed throughout Mediterranean region but most profoundly present in South Africa (Miller, 2002). P. graveolens is a source of high-quality essential oil (EO) that is rich in citronellol and geraniol. P. graveolens EO is commonly known as geranium oil and is extensively used as perfumes and in skin care products. P. graveolens EO is also used in aromatherapy, and pharmacologically, it acts as antibacterial, antifungal, insect repellent, and has skin cleansing properties (Pattnaik, Subramanyam and Kole, 1996; Pattnaik, Subramanyam, Bapaji and Kole, 1997; Rao Rajeswara, Kaul, Mallavarapu and Ramesh, 1996; Lis-Balchin, Buchbauer, Ribisch and Wenger, 1998; LisBalchin, Steyrl and Krenn, 2003). In the present research work, an attempt has been made to determine the chemical composition of EO from leaves of $P$. graveolens by gas chromatography-mass spectrometry (GC-MS). The present study was also designed to evaluate its antidiabetic activity through inhibition of $\alpha$-glucosidase enzyme.

\section{Materials AND Methods}

\section{A. Plant Materials and Chemicals}

The fresh leaves of $P$. graveolens $(500 \mathrm{~g})$ were collected in the month of March 2020 from local market of Erbil, Kurdistan Region, Iraq. The authenticity of all the accession was ascertained by Taxonomist. The plant sample was kept in the Faculty of Pharmacy, Tishk International University, Erbil, Iraq. For future reference (voucher number: PRL/2020/07), $p$-Nitrophenyl- $\alpha$-D-glucopyranoside (PNPG), 3,5-dinitrosalicylic acid (DNS), acarbose, and $\alpha$-glucosidase enzyme were brought from Subra Scientific Company, Chennai, India. All other solvents and chemicals used in the study were of analytical grade

\section{B. Isolation of EO from Leaves of P. graveolens}

The fresh $P$. graveolens leaves $(500 \mathrm{~g})$ were hydrodistilled for $6 \mathrm{~h}$ in Clevenger apparatus. After isolation of EO, the volatile oil was collected in the graduated tube and dried over anhydrous sodium sulfate and stored at $4{ }^{\circ} \mathrm{C}$ in a refrigerator for further use.

\section{GC-MS Analysis and Identification of Chemical Constituents}

The chemical composition of $P$. graveolens EO was determined by the GC-MS method. Agilent Bench Top GC-MS (Agilent Technologies, Wilmington, DE, USA) equipment with a capillary column of DB-5 glass (specifications $30 \mathrm{~m} \times 2.5 \mathrm{~mm}$ i.d; film thickness of $0.25 \mu \mathrm{m}$ ) was applied for test sample analysis. Helium was used as carrier gas at flow rate of $1 \mathrm{~mL} / \mathrm{min}$. The oven temperature was set at $50^{\circ} \mathrm{C}$ for $1 \mathrm{~min}$ and then holds isothermally for $2 \mathrm{~min}$ at $320^{\circ} \mathrm{C}$. The temperature of injector port was maintained at $250^{\circ} \mathrm{C}$, and ion source temperature was kept at $200^{\circ} \mathrm{C}$, and interface temperature was maintained at $300^{\circ} \mathrm{C}$. The EO $(1 \mu \mathrm{L})$ was injected and the split ratio was kept at 1:5. Data capture took place at $70 \mathrm{eV}$ using scanning times of $1.5 \mathrm{~s}$ in the mass range of 50-1000 amu and run time was kept up to $38 \mathrm{~min}$. The chromatography and mass spectra were handled with ChemStation software (Agilent Technologies, Wilmington, DE, USA).

The individual peaks/constituents were identified by comparison of their Kovats index (K.I.) with those of literature in close agreement to K.I. Further identification of EO constituents was made by comparison of the fragmentation pattern of mass spectra obtained by $\mathrm{GC} /$ MS analysis with those stored in the spectrometer database of NIST, NBS 54 K.L, WILEY8 libraries, and published literature (Adams, 2007; Ali, 2001; Rana, et al., 2002; Bhattacharya, Kaul, Rao, Ramesh and Mallavarapu, 1993; Abd El-Kareem, Rabbih, Elansary and Al-Mana, 2020). The percent composition of the EO compounds was calculated. The qualitative analysis was based on the percent area of each peak of the sample compounds.

\section{In vitro $\alpha$-Glucosidase Inhibitory Activity}

Antidiabetic activity of EO of $P$. graveolens was assessed through $\alpha$-glucosidase inhibition assay. The assay method briefly summarized as $60 \mu \mathrm{L}$ of EO of P. graveolens in DMSO with concentrations ranging from 31.25 to $1000 \mu \mathrm{g} / \mathrm{mL}$ and $0.1 \mathrm{M}$ phosphate buffer $(50 \mathrm{~mL}$; pH 6.8) containing $\alpha$-glucosidase solution $(0.2 \mathrm{U} / \mathrm{mL})$ was incubated at $37^{\circ} \mathrm{C}$ for $20 \mathrm{~min}$ in 96-well plates. PNPG $(50 \mathrm{~mL} ; 5 \mathrm{mM})$ solution in a $0.1 \mathrm{M}$ phosphate buffer $(\mathrm{pH}$ 6.8) was applied to each well after pre-incubation and further incubated for $20 \mathrm{~min}$ at $37^{\circ} \mathrm{C}$. Then, the reaction was stopped by adding $160 \mathrm{~mL}$ of $0.2 \mathrm{M} \mathrm{NaCO}_{3}$ into each well. Absorbance (A) was reported at $405 \mathrm{~nm}$ with microplate reader and compared to a control which had $60 \mu \mathrm{L}$ of buffer solution in place of the test sample. Acarbose was used as a standard drug and evaluated same way as the test sample (Ahamad, Alkefai, Amin and Mir, 2020). The $\%$ inhibition of $\alpha$-glucosidase enzyme was calculated using the following formula:

$$
\% \text { Inhibition }=\frac{\text { Abs control }- \text { Abs test }}{\text { Abs control }} \times 100
$$

where, Abs is absorbance of the control and absorbance of the sample

\section{RESUltS AND Discussion}

\section{A. GC-MS Analysis of EO of P. graveolens}

The EO from leaves of $P$. graveolens was isolated by the hydrodistillation method. The hydrodistillation yielded $0.45 \%$ of EO from leaves of $P$. graveolens. The chemical composition of EO of $P$. graveolens was determined by the GC-MS method and results are presented in Table I and Fig. 1. Thirty-six components representing 99.17\% of the total detected constituent were identified. The major constituents in the EO of $P$. graveolens include 


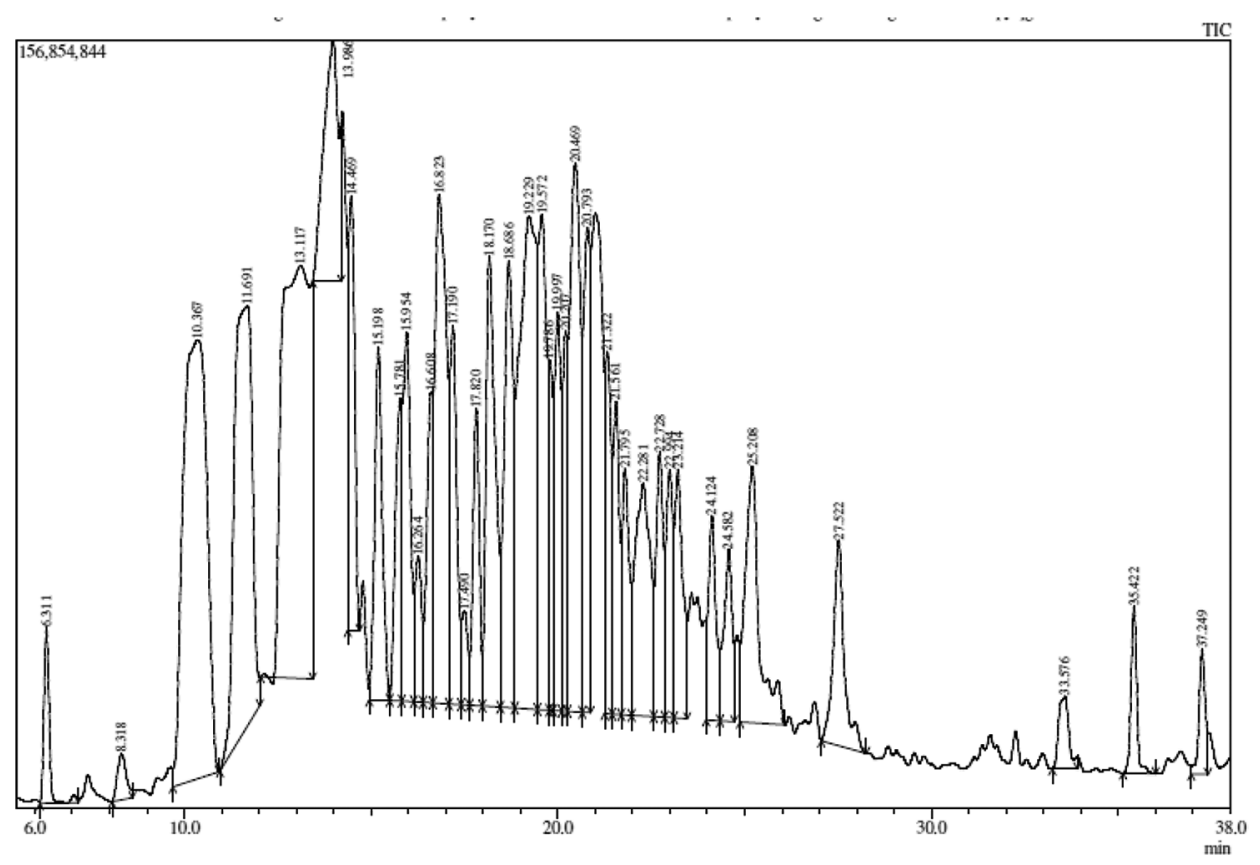

Fig. 1. Gas chromatography-mass spectrometry chromatogram of essential oil of Pelargonium graveolens.

citronellyl isovalerate $(10.41 \%)$, menthol $(9.61 \%)$, linalool $(8.63 \%), p$-menthone $(6.31 \%)$, geranyl tiglate $(4.99 \%)$, neryl propionate $(4.79 \%)$, isocaryophyllene $(3.77 \%)$, and caryophyllene epoxide $(3.63 \%)$. The other components of $P$. graveolens EOs are geranyl butyrate $(3.50 \%)$, neryl hexanoate $(2.98 \%)$, geranyl heptanoate $(2.93 \%)$, heptaminol (2.92\%), citronellyl hexanoate $(2.64 \%)$, neryl acetate $(2.32 \%)$, myrtanol $(2.23 \%)$, citronellol $(2.22 \%)$, and nerolidyl acetate $(2.18 \%)$. Other minor chemical components $(<2 \%)$ of EO of $P$. graveolens are also presented in Table I. Rana, et al. studied the EO composition of $P$. graveolens leaves from Uttarakhand, India. The results show that citronellol (33.6\%), geraniol (26.8\%), linalool (10.5\%), citronellyl formate (9.7\%), and $p$-menthone $(6.0 \%)$ were major chemical components in EO (Rana, et al., 2002). Bhattacharya, et al. (1993) studied volatile oil components of rose-scented Geranium and found that citronellol (25.44\%), geraniol (21.87\%), and linalool $(7.87 \%)$ as major chemical compounds. In another study, EO components of $P$. graveolens from Egypt were studied by GC-MS. The study also shows citronellol (27.67\%), cis-Menthone (10.23\%), linalool (10.05\%), eudesmol (9.40\%), geraniol formate $6.87 \%$, and rose oxide $(5.77 \%)$ as major constituents (Abd ElKareem, Rabbih, Elansary and Al-Mana, 2020). The present research is the first study on EO composition of Geranium growing in Iraqi Kurdistan. The study shows the presence of derivatives of citronellyl and geraniol, the major components already reported by other researchers such as citronellyl isovalerate $(10.41 \%)$ and geranyl tiglate $(4.99 \%)$. The present study finding is also comparable with the previous findings as study shows the presence of menthol $(9.61 \%)$, linalool $(8.63 \%)$, and $p$-menthone
$(6.31 \%)$ as other major components. The variation in the chemical composition of Geranium is maybe due to variations in geographical location, temperature, rainfall, soil, etc. (Ahamad, Uthirapathy, Ameen and Anwer, 2019).

\section{B. $\alpha$-Glucosidase Inhibition Activity of EO of P. graveolens}

The EO of $P$. graveolens showed concentration-dependent $\alpha$-glucosidase enzyme inhibition that varies from $28.13 \pm$ 1.41 to $74.24 \pm 2.53 \%$ for concentration ranging from 31.25 to $1000 \mu \mathrm{g} / \mathrm{mL}$ (Table II and Fig. 2). Acarbose was used as positive standard and it also showed concentration-dependent inhibition of $\alpha$-glucosidase enzyme inhibition ranging from $31.94 \pm 2.45$ to $81.26 \pm 3.21 \%$ for the same concentration as test sample above. The $\mathrm{IC}_{50}$ values for $P$. graveolens and acarbose were found as $93.72 \pm 4.76$ and $80.4 \pm 2.17 \mu \mathrm{g} / \mathrm{mL}$, respectively, against $\alpha$-glucosidase enzyme.

The results of enzyme inhibition assay indicate that the EO of $P$. graveolens inhibits $\alpha$-glucosidase enzyme in in vitro study. The results also show that the EO of $P$. graveolens was found comparable with standard acarbose in inhibition of $\alpha$-glucosidase enzyme. $\alpha$-Amylase and $\alpha$-glucosidase enzymes are present in brush border of gastrointestinal tract and responsible for breakdown of polysaccharides and disaccharides, respectively. Inhibition of these enzymes leads reduction of monosaccharides available for absorption in blood and ultimately it controls sudden rise of blood glucose level after meals. The increased blood sugar level after a meal is known as PPHG and controlling it by inhibiting $\alpha$-glucosidase enzyme is a new strategy in management of type 2 diabetes. The inhibitors of $\alpha$-amylase and $\alpha$-glucosidase enzymes such as acarbose and miglitol are nonspecific in their action, the strong inhibition of both enzymes leads decreased metabolism of polysaccharides which causes 
TABLE I

Chemical COMposition of ESSENTIAL oil of $P$. GRAVEOLENS

\begin{tabular}{lccc}
\hline \hline Chemical constituents & RT & KI & Concentration (\%) \\
\hline p-Cymene & 6.311 & 1026 & 0.78 \\
Limonene & 8.318 & 1031 & 0.34 \\
Linalool & 10.367 & 1097 & 8.63 \\
p-Menthone & 11.691 & 1153 & 6.31 \\
Menthol & 13.117 & 1173 & 9.61 \\
Heptaminol & 13.986 & 1188 & 2.92 \\
Citronellol & 14.469 & 1226 & 2.22 \\
Myrtanol & 15.198 & 1259 & 2.23 \\
Citronellyl acetate & 15.781 & 1353 & 1.57 \\
Neryl acetate & 15.954 & 1365 & 2.32 \\
a-Copaene & 16.264 & 1376 & 0.79 \\
Isocaryophyllene & 16.608 & 1413 & 3.77 \\
Neryl propionate & 17.190 & 1428 & 4.79 \\
Epoxy cholesterol & 17.490 & - & 0.48 \\
a-Himachalene & 17.820 & 1447 & 1.57 \\
Geranyl butyrate & 18.170 & 1562 & 3.50 \\
Citronellyl isovalerate & 19.229 & 1563 & 10.41 \\
Caryophyllene epoxide & 19.572 & 1581 & 3.63 \\
Epicubenol & 19.786 & 1613 & 0.99 \\
Nerolidyl acetate & 19.997 & 1632 & 2.18 \\
Cubenol & 20.207 & 1641 & 1.44 \\
Geranyl tiglate & 20.469 & 1700 & 4.99 \\
Citronellyl hexanoate & 20.793 & 1702 & 2.64 \\
Citronellyl cinnamate & 21.322 & - & 1.78 \\
Geranyl hexanoate & 21.561 & 1725 & 1.65 \\
Kauren-19-yl-acetate & 21.795 & - & 1.43 \\
Geranyl heptanoate & 22.281 & 1824 & 2.93 \\
1-Hexadecanol & 22.728 & 1868 & 1.58 \\
3,7-Dimethyloct-6-en-1-yl heptanoate & 22.994 & - & 1.40 \\
2,6-Octadien-1-ol, 3,7-dimethyl-, propanoate & 23.214 & 1831 & 1.68 \\
Citronellyl valerate & 24.124 & 1880 & 1.31 \\
Hexadecanoic acid & 24.582 & 1972 & 1.18 \\
Neryl hexanoate & 25.208 & 2031 & 2.98 \\
Methyl linolenate & 27.522 & 2098 & 1.87 \\
2-Methylhexacosane & 33.576 & 2663 & 0.61 \\
Tetrapentacontane & 35.422 & - & 0.66 \\
\hline \hline & & & \\
\hline & & & \\
\hline & & &
\end{tabular}

Where, RT: Retention time, and KI: Kovats index

TABLE II

A-GLUCOSIDASE ENZYME INHIBITORY ACTIVITY OF EO FROM LEAF OF P. GRAVEOLENS

\begin{tabular}{lcc}
\hline \hline Conc. $(\mu \mathrm{g} / \mathrm{mL})$ & Acarbose & P. graveolens \\
\hline 31.25 & $31.94 \pm 2.45$ & $28.13 \pm 1.41$ \\
62.5 & $45.44 \pm 2.63$ & $41.72 \pm 0.93$ \\
125 & $57.23 \pm 3.31$ & $55.17 \pm 3.46$ \\
250 & $63.82 \pm 2.47$ & $59.03 \pm 2.45$ \\
500 & $76.81 \pm 2.96$ & $63.28 \pm 2.45$ \\
1000 & $81.26 \pm 3.21$ & $74.24 \pm 2.53$ \\
IC $_{50}$ values & $80.4 \pm 2.17$ & $93.72 \pm 4.76$ \\
\hline \hline
\end{tabular}

Data were presented as mean of $\%$ inhibition in triplicate determinations \pm SD

flatulence and distension as side effects due to bacterial fermentation from undigested carbohydrates (Subramanian, Asmawi and Sadikun, 2008; Dong, Li, Zhu, Liu and Huang, 2012). The present study finding supports the potential antidiabetic effects of $P$. graveolens EO in controlling PPHG through inhibition of $\alpha$-glucosidase enzyme.

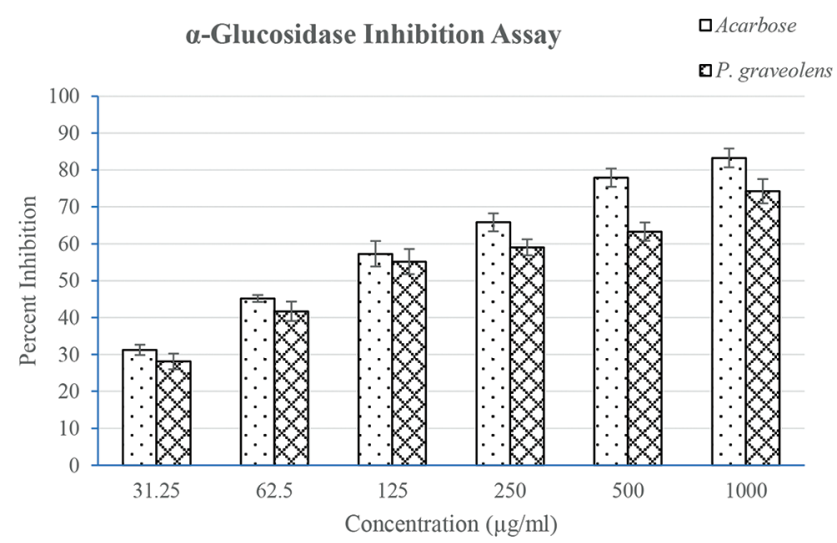

Fig. 2. $\alpha$-Glucosidase enzyme inhibitory activity of essential oils from the leaf of Pelargonium graveolens.

\section{CONCLUSION}

GC-MS analysis of Kurdish $P$. graveolens EO yielded citronellyl isovalerate, menthol, linalool, $p$-menthone, and geranyl tiglate as major constituents. P. graveolens EO also found potent inhibitors of $\alpha$-glucosidase enzyme. The current research is first reports on the chemical composition of $P$. graveolens growing in Iraqi Kurdistan region. The findings of the present study also provide a scientific basis for its use in diabetic patients for controlling PPHG.

\section{ACKNOWLEDGMENT}

We gratefully acknowledge the Tishk International University, Erbil, Iraq, for providing research facilities. We also acknowledge Trichy Research Institute of Biotechnology Pvt. Ltd., Trichy, Tamil Nadu, India, for providing the research facilities.

\section{REFERENCES}

Abd El-Kareem, M.S.M., Rabbih, M.A., Elansary, H.O. and Al-Mana, F.A., 2020. Mass spectral fragmentation of Pelargonium graveolens essential oil using GCMS semi-empirical calculations and biological potential. Processes, 8, p.128.

Adams, R.P., 2007. Identification of Essential Oil Components by Gas Chromatography/Mass Spectrometry. $4^{\text {th }}$ ed. Allured Publishing, Carol Stream, IL, USA.

Ahamad, J., Alkefai, N.H.A., Amin, S. and Mir, S.R., 2020. Standardized extract from Enicostemma littorale ameliorates post-prandial hyperglycaemia in normal and diabetic rats. Journal of Biologically Active Products from Nature, 10(1), pp.34-43.

Ahamad, J., Hasan, N., Amin, S. and Mir, S.R., 2016. Swertiamarin contributes to glucose homeostasis via inhibition of carbohydrate metabolizing enzymes. Journal of Natural Remedies, 16(4), pp.125-130.

Ahamad, J., Naquvi, K.J., Mir, S.R. and Ali, M., 2011. Review on role of natural alpha-glucosidase inhibitors for management of diabetes mellitus. International Journal of Biomedical Research, 6, pp.374-380.

Ahamad, J., Toufeeq, I., Khan, M.A., Ameen, M.S.M., Anwer, E.T., Uthirapathy, S., Mir, S.R. and Ahmad, J., 2019. Oleuropein: A natural antioxidant molecule in the treatment of metabolic syndrome. Phytotherapy Research, 33(12), pp.3112-3128.

Ahamad, J., Uthirapathy, S., Ameen, M.S.M. and Anwer, E.T., 2019. Essential 
oil composition and antidiabetic, anticancer activity of Rosmarinus officinalis L. leaves from Erbil (Iraq). Journal of Essential Oil Bearing Plants, 22(6), pp.1544-1553.

Ali, M., 2001. Techniques in Terpenoid Identification. Birla Publication, New Delhi, India, pp.4-51.

Alkefai, N.H., Ahamad, J., Amin, S. and Mir, S.R., 2018. Arylated gymnemic acids from Gymnema sylvestre R.Br. as potential $\alpha$-glucosidase inhibitors. Phytochemistry Letters, 25, pp.196-202.

Alkefai, N.H., Sharma, M., Ahamad, J., Amin, S. and Mir, S.R., 2019. New olean15-ene type gymnemic acids from Gymnema sylvestre (Retz.) R.Br. and their antihyperglycemic activity through $\alpha$-glucosidase inhibition. Phytochemistry Letters, 32, pp.83-89.

Bhattacharya, A.K., Kaul, P.N., Rajeswara, B.R.R., Ramesh, S.I. and Mallavarapu, G.R., 1993. Composition of the oil of rose-scented Geranium (Pelargonium sp.) grown under the semiarid tropical climate of South India. Journal of Essential Oil Research, 5(2), pp.229-231.

Dong, H.Q., Li, M., Zhu, F., Liu, F.L. and Huang, J.B., 2012. Inhibitory potential of trilobatin from Lithocarpus polystachyus rehd against $\alpha$-glucosidase and $\alpha$-amylase linked to Type 2 diabetes. Food Chemistry, 130, pp.1261-66.

Fabricant, D.S. and Farnsworth, N.R., 2001. The value of plants used in traditional medicine for drug discovery. Environmental Health Perspectives, 109(1), pp.69-75.

Gin, H., and Rigalleau, V., 2000. Post-prandial hyperglycemia and diabetes. Diabetes and Metabolism, 26, pp.265-272.

Lis-Balchin, M., Buchbauer, G., Ribisch, K. and Wenger, M.T., 1998. Comparative antibacterial effects of novel Pelargonium essential oils and solvent extracts. Letters in Applied Microbiology, 27(3), pp.135-141.

Lis-Balchin, M., Steyrl, H. and Krenn, E., 2003. The comparative effect of novel Pelargonium essential oils and their corresponding hydrosols as antimicrobial agents in a model food system. Phytother. Phytotherapy Research, 17(1), pp.60-65.

Miller D.M., 2002. Geranium and Pelargonium. In: Lis-Balchin, M., Ed. Medicinal and Aromatic Plants-Industrial Profiles. Taylor and Francis, London, UK, p.49.

Pattnaik, S., Subramanyam, V.R. and Kole, C.R., 1996. Antibacterial and antifungal activity of ten essential oils in vitro. Microbios, 86, p.237.

Pattnaik, S., Subramanyam, V.R., Bapaji, M. and Kole, C.R., 1997. Antibacterial and antifungal activity of aromatic constituents of essential oils. Microbios, 89(358), pp.39-46.

Rajeswara, B.R.R., Kaul, P.N., Mallavarapu, G.R. and Ramesh, S., 1996. Effect of seasonal climatic changes on biomass yield and terpenoid composition of rose-scented geranium (Pelargonium species). Biochemical Systematics and Ecology, 24(7-8), pp.627-635.

Rana, V.S., Juyal, J.P. and Blazquez, M.A., 2002. Chemical constituents of essential oil of Pelargonium graveolens leaves. International Journal of Aromatherapy, 12(4), pp.216-218.

Scheen, A.J. 2003. Is there a role for $\alpha$-glucosidase inhibitors in the prevention of Type 2 diabetes mellitus? Drugs, 63, pp.933-951.

Subramanian, R., Asmawi, M.Z. and Sadikun, A., 2008. In-vitro $\alpha$-glucosidase and $\alpha$-amylase enzyme inhibitory effects of Andrographis paniculata extract and andrographolide. Acta Biochimica Polonica, 55(2), pp.391-398. 